\title{
Application of auditory cortical evoked potentials for auditory assessment in people using auditory prosthesis
}

\author{
JIAN-HUA DENG, JI-HONG DU, XIN-RUI MA and PEI-FANG ZHANG
}

Department of Otolaryngology, The First People's Hospital of Kunshan, Kunshan, Jiangsu 215300, P.R. China

Received April 08, 2018; Accepted August 08, 2018

DOI: $10.3892 / \mathrm{etm} .2018 .7140$

\begin{abstract}
The present study explored the application of auditory cortical evoked potentials (ACEP) in the auditory assessment of people using an auditory prosthesis. There were 126 patients with prelingual deafness who were selected from January 2012-June 2017 from the First People's Hospital of Kunshan (Kunshan, China). HEARLab ${ }^{\text {TM }}$ system was used to induce a P1-N1-P2 waveform under the condition of $60 \mathrm{~dB}$ sound pressure level at $/ \mathrm{m} /, / \mathrm{g} /$ and $/ \mathrm{t} /$ acoustic stimulations. Speech production ability and auditory perception ability of patients were evaluated by speech intelligibility rating (SIR) and categories of auditory performance (CAP). Extraction rate of $\mathrm{P} 1$ waves of patients with auditory prosthesis was higher than that of N1 and P2 waves under different acoustic stimulations. A younger initial age and shorter deafness duration before patients used an auditory prosthesis led to more marked P1-N1-P2 waveforms and longer P1 latencies. At $/ \mathrm{m} /$ acoustic stimulation, P1 latency and amplitude were negatively associated with the usage time of auditory prosthesis. There were significant differences in the results of SIR and CAP and the initial age of use of auditory prosthesis and deafness duration before patients used the auditory prosthesis. These findings suggest that ACEP can be used to evaluate the auditory assessment of people using an auditory prosthesis. The initial age of use of an auditory prosthesis and deafness duration can affect the P1-N1-P2 waveform and P1 latency of prelingual deafness.
\end{abstract}

\section{Introduction}

As with the visual system, the auditory system can locate the source of stimuli in space and distinguish between different

Correspondence to: Dr Ji-Hong Du, Department of Otolaryngology, The First People's Hospital of Kunshan, 91 Qianjin West Road, Kunshan, Jiangsu 215300, P.R. China

E-mail: dujihong_djh@126.com

Key words: auditory cortical evoked potential, auditory prosthesis, P1 wave, latency, amplitude, acoustic stimulation, speech intelligibility rating, categories of auditory performance stimuli (1). Hearing loss is one of the most common birth defects (2). Prelingual deafness is a type of hearing loss and is a profound hearing impairment that is congenital or occurs in the first few years of life, which is fully acquired prior to language and speech and can result in brain structure alterations $(3,4)$. It typically takes place prior to 2 years of age with a high rate of incidence (5). More than $60 \%$ of patients with prelingual deafness are associated with hereditary factors and the other $40 \%$ are associated with environmental or iatrogenic factors $(2,6)$. Cochlear implantation (CI) serves an essential role in patients with severe hearing loss of hearing ability and verbal ability as CI enables patients to have the stimulation sound to promote auditory center development and interfere with auditory cortex alienation $(7,8)$. The assessment of prelingual auditory development is very important in early identification and for interventions to treat hearing impairment and deafness (9). The current predominant methods of evaluating hearing aid effects in the clinic are sound field audiometry, speech audiometry and subjective evaluation (10), which have large limitations.

Auditory cortical evoked potential (ACEP) is a novel method of evaluating hearing loss in children who do not receive reliable feedback to all external sounds (11). ACEP has some of the most common exogenous waves, including P1, N1 and P2, which provide information about sound information's arrival to the auditory cortex (12). P1 latency is a useful biomarker of central auditory development and a powerful, positive response that is easily identified, which occurs following 100-300 msec of stimulation depending on the age of the child $(13,14)$. Additionally, N1 is a high negative peak at $\sim 100 \mathrm{msec}$ following the stimulus initiation, but P2 is a second high positive peak at $200 \mathrm{msec}$ following stimulus (12). N1 initially emerges in the P1 waveform as a bifurcation, which serves as a biomarker of higher-order auditory cortical development (15). The P1-N1-P2 waveform pattern for people with auditory deficits had been illustrated to result from the absence of a synchronized neural response to a stimulus characteristic, whose responses had association with acoustic changes in speech sounds $(16,17)$. Therefore, the present study was conducted to evaluate the effect of the exogenous P1-N1-P2 waves on the ACEP of people with auditory prosthesis and to evaluate ACEP feasibility in clinical practice for assessing the application value of auditory effects. 


\section{Materials and methods}

Ethics statement. All research subjects in the present study met the inclusion and exclusion criteria. In addition, the present study was approved by the Ethics Committee of the First People's Hospital of Kunshan (Kunshan, China), and all patients provided written informed consent.

Subjects. From January 2012-June 2017, 126 prelingual deaf patients (aging from 1-18 years old) from The First People's Hospital of Kunshan (Kunshan, China), were evaluated, including 67 males and 59 females with a mean age of $9.1 \pm 2.8$ years. There were 69 cases of patients with hearing aids and 57 cases of patients with CI, in which the minimum age of using auditory prosthesis was 6 months and the maximum age was 18 years. In addition, the duration of using auditory prosthesis was 1-9 years, and the mean duration was $8.8 \pm 0.8$ years. The medical evaluation of 126 prelingual deaf patients was performed for otoscopy canal patency and tympanic membrane integrity. Additionally, computed tomography (CT) was used to examine congenital inner ear malformations. Audiological assessment for pure tone audiometry determined that phono-sensitive neural hearing was lost $(>90 \mathrm{~dB})$ and auditory brainstem response test had no evoked potential being extracted ( $>95 \mathrm{dBnHL}$ ); distortion product otoacoustic emissions were not led out. The acoustic impedance test tympanogram presented with B type or C type curves, with acoustic reflection that disappeared; language and language development were hindered by language barriers; the symptoms were diagnosed as binaural extremely severe sensorineural deafness (18). Inclusion criteria of study subjects were as follows: Patients' details included basic information, the epicophosis history and other clinical data; patients aged between 1 and 18 years; patients with binaural extremely severe sensorineural deafness (pure-tone average $>90 \mathrm{~dB}$ ); the use of auditory prosthesis for $>6$ months and the auditory language ability being significantly improved; the patient and their guardian having a correct understanding of the present study and voluntary participation in the study. The presence of non-hearing factors in patients with congenital disease lead to exclusion. Table I presents the base characteristics of 126 patients using auditory prosthesis.

ACEP test. ACEP of all enrolled subjects was tested using the HEARLab $^{\mathrm{TM}}$ system (Frye Electronics, Inc., Beaverton, OR, USA). The tests were conducted in a sound insulation room in the Ear-Nose-Throat Department of the First People's Hospital of Kunshan in which the indoor temperature was $25^{\circ} \mathrm{C}$, the relative humidity was $30-50 \%$ and the background noise was $<30 \mathrm{~dB}$. In the testing process, the patients were permitted to sit in a more comfortable position and were instructed to watch a silent animation in order to stay alert and quiet, to minimize physical activity, and to rest when not in a good condition. All of these were performed to ensure that the test results were true and reliable.

An ethanol solution with a volume fraction of $95 \%$ was used to wipe the body part of the receiver's electrode and remove pollutants of grease and dandruff and other pollutants prior to testing. The recording electrode, grounding electrode, and reference electrode were placed in the middle of the
Table I. Basic information of 126 patients with auditory prosthesis.

\begin{tabular}{lc} 
Characteristics & Patients \\
\hline Age (years) & \\
$\leq 10$ & 78 \\
$>10$ & 48 \\
Duration of deafness (years) & \\
$\leq 10$ & 85 \\
$>10$ & 41 \\
Age at initial use of auditory prosthesis (years) & \\
$\leq 8$ & 71 \\
$>8$ & 55 \\
Location of an auditory prosthesis & \\
Auris sinistra & 65 \\
Auris dextra & 61
\end{tabular}

calvarium, the middle of forehead, ear and mastoid synapse without being on the side of the auditory prosthesis in which electrode impedance should be $<5 \mathrm{k} \Omega$.

Once the HEARLab ${ }^{\mathrm{TM}}$ system was opened and logged under the normal working conditions of the auditory prosthesis, the basic information of the subjects was entered, ACA was chosen as the test pattern, and test conditions were as those for an auditory prosthesis. Then, the calibrated sound field was pressed. The speaker distance from subjects was $1.5 \mathrm{~m}$, both being placed at the angle of $90^{\circ}$, in which the speaker and receiver test ear were at the same level. The initial test strength was calibrated as $60 \mathrm{~dB}$ sound pressure level. $/ \mathrm{m} /, / \mathrm{g} /$ and $/ \mathrm{t} /$ were used as the stimulus sound, which represented the stimulation of low frequency $(0.2-0.5 \mathrm{kHz})$, intermediate frequency $(0.8-1.6 \mathrm{kHz})$, and high frequency $(2-8 \mathrm{kHz})$, and the duration time was 30 , 30 , and $20 \mathrm{msec}$, respectively, with $1,125 \mathrm{msec}$ as a repeat circle. Additionally, the waveform window time included $200 \mathrm{msec}$ prior to stimulation sound, $600 \mathrm{msec}$ following stimulation sound, and the artifact rejection range was $\pm 150 \mathrm{mv}$, in which superposition times were 2 times/sec. The waveform was extracted by judging the P-value according to system automatic statistical analysis and was extracted when $\mathrm{P}<0.05$. Each stimulus was tested 2 times, recording subjects' amplitude and incubation of P2, N1 and P1 under 3 types of stimulation sounds.

Gauge score records. In the present study, speech intelligibility rating (SIR) and categories of auditory performance (CAP) established by the University of Nottingham (19) were used to conduct grading evaluation of speech production and auditory perception in all patients with auditory prosthesis. SIR (Table II) and CAP (Table III) were divided into 1-5 and 1-8 levels, respectively, according to the extent to which patients' self-speaking with auditory prosthesis was understood and the hearing level in daily life. Both scores were obtained through face-to-face investigation or telephone follow-up of the patients themselves and relatives who had close contact with the patients in their daily lives. 
Table II. Speech intelligibility rating.

\begin{tabular}{ll} 
Grade & \multicolumn{1}{c}{ Judgment standards } \\
\hline 5 & Coherent speech could be understood by all people, and children's language is easy to understand in daily contexts \\
4 & Coherent speech could be understood by a person who had not spoken to the deaf \\
3 & Coherent speech could be understood with listener's concentration combined with lipreading \\
2 & Coherent speech could not be understood by listener, but a few words could be understood based on condition of \\
1 & context and lipreading \\
& Daily speech could not be understood by anyone, and the main method of communication is gesture
\end{tabular}

Table III. Categories of auditory performance (28).

\begin{tabular}{ll}
\hline Grade & \multicolumn{1}{c}{ Judgment standards } \\
\hline 8 & Using telephone to chat with familiar people \\
7 & Chatting with others without lipreading \\
6 & Understanding common statements without lipreading \\
5 & Differentiating speech sound without lipreading \\
4 & Distinguishing environment sound \\
3 & Having response to speech (example: Walking) \\
2 & Being aware of the sound in the environment \\
1 & Being unaware of the sound in the environment \\
\hline
\end{tabular}

Statistical analysis. All data were processed using SPSS 20.0 statistical software (IBM Corp. Armonk, N.Y., USA), and the measurement data were expressed as the mean \pm standard deviation. Data with normal distribution and homogenous variance were analyzed with an independent sample t-test; whereas data that did not conform to normal distribution or homogeneous variance were analyzed with the Wilcoxon rank-sum test. Two groups of different acoustic stimulations were analyzed by repeated measures of one-way analysis of variance. Post hoc test was performed using the Bonferroni test. Categorical data were expressed as percentage or rate and analyzed using $\chi^{2}$ test. Correlation analysis was conducted via Pearson correlation analysis. All tests were two-tailed and $\mathrm{P}<0.05$ was considered to indicate a statistically significant difference.

\section{Results}

Extraction rates of $P 1$ and $N 1, P 1$ and $P 2$ waves of patients using auditory prosthesis under different acoustic stimulations are different. Initially, the extraction rates of different waves were compared under different stimuli in patients with hearing aids. Table IV and Fig. 1 present the results of extraction rates of $\mathrm{P} 1, \mathrm{~N} 1$ and $\mathrm{P} 2$ waves of patients using auditory prosthesis under different acoustic stimulations. With different acoustic stimulations of $/ \mathrm{m} /, / \mathrm{g} /$ and $/ \mathrm{t} /$, extraction rates of $\mathrm{P} 1$ and N1 wave were significantly different $\left(\chi^{2}=57.040\right.$; $\chi^{2}=52.310 ; \chi^{2}=66.030 ;$ all $\left.\mathrm{P}<0.05\right)$; there was also a significant difference between the extraction rates of $\mathrm{P} 1$ and $\mathrm{P} 2$ waves $\left(\chi^{2}=67.640 ; \chi^{2}=57.670 ; \chi^{2}=90.570 ;\right.$ all $\left.\mathrm{P}<0.05\right)$, however, no significant difference was observed between the extraction

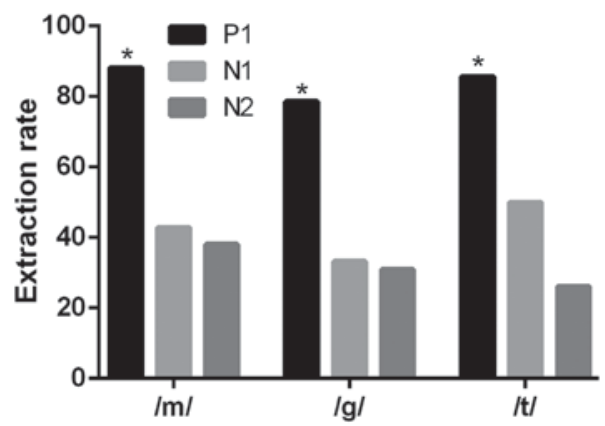

Figure 1. Extraction rate of P1, N1 and P2 waves under different acoustic stimulations. Data are presented as a percentage and analyzed via $\chi^{2}$ test. ${ }^{*} \mathrm{P}<0.05$ vs. $\mathrm{N} 1$ and $\mathrm{P} 2$.

rates of P2 and N1 waves $\left(\chi^{2}=0.593 ; \chi^{2}=0.164 ; \chi^{2}=2.674 ;\right.$ all $\mathrm{P}>0.05$ ).

Pl wave growth of auditory prosthesis users is affected by initial age of using the device. The influence of age on P1-N1-P2 waveforms and P1 latency was then investigated. Under different acoustic stimulations, P1-N1-P2 waveforms were relatively typical for 126 patients who began using auditory prosthesis at the age of $\leq 8$ or $>8$ years old (Fig. 2). Under the acoustic stimulations of $/ \mathrm{m} /, / \mathrm{g} /$ and $/ \mathrm{t} /$, the target subjects of two groups $(\leq 8$ or $>8)$ presented a significant difference in $\mathrm{P} 1$ latency (all $\mathrm{P}<0.017$ ) following correction via the Bonferroni method (Table V), which suggested that the P1 wave growth of auditory prosthesis users was affected by their initial age of using the device; that earlier initial use was better for auditory pathway remolding.

Deafness duration affects waveforms of P1-N1-P2 and $P 1$ latency. The effect of deafness duration on P1-N1-P2 waveform and P1 latency was also explored. Under different acoustic stimulations, the different P1-N1-P2 waveforms were observed between patients who had $\leq 10$ years of deafness and those who had $>10$ years of deafness prior to using an auditory prosthesis (Fig. 3). Compared with the patients who had $\leq 10$ years of deafness, the waveforms were not typical for those with $>10$ years of deafness. Under the acoustic stimulations of $/ \mathrm{m} /, / \mathrm{g} /$ and $/ \mathrm{t} / \mathrm{P} 1$ latency of patients in the two groups was increased significantly $(\mathrm{P}<0.017$; Table VI).

Latency and amplitude of the Pl wave were negatively associated with usage time of auditory prosthesis. Correlation 
Table IV. Extraction rates of P1, N1 and P2 wave under different acoustic stimulations.

\begin{tabular}{lcccccccc}
\hline & \multicolumn{2}{c}{$/ \mathrm{m} /$} & \multicolumn{2}{c}{$/ \mathrm{g} /$} & & \multicolumn{2}{c}{$/ \mathrm{t} /$} \\
\cline { 2 - 3 } \cline { 7 - 8 } Wave & Extracted (\%) & Not extracted (\%) & & Extracted $(\%)$ & Not extracted (\%) & & Extracted (\%) & Not extracted (\%) \\
\hline P1 & $111(88.1)$ & $15(11.9)$ & & $99(78.6)$ & $27(21.4)$ & & $108(85.7)$ & $18(14.3)$ \\
N1 & $54(42.9)$ & $72(57.1)$ & & $42(33.3)$ & $84(66.7)$ & & $45(35.7)$ & $81(64.3)$ \\
P2 & $48(38.1)$ & $78(61.9)$ & & $39(31.0)$ & $87(69.0)$ & & $33(26.2)$ & $93(73.8)$ \\
\hline
\end{tabular}

Data are presented as $\mathrm{n}(\%)$.

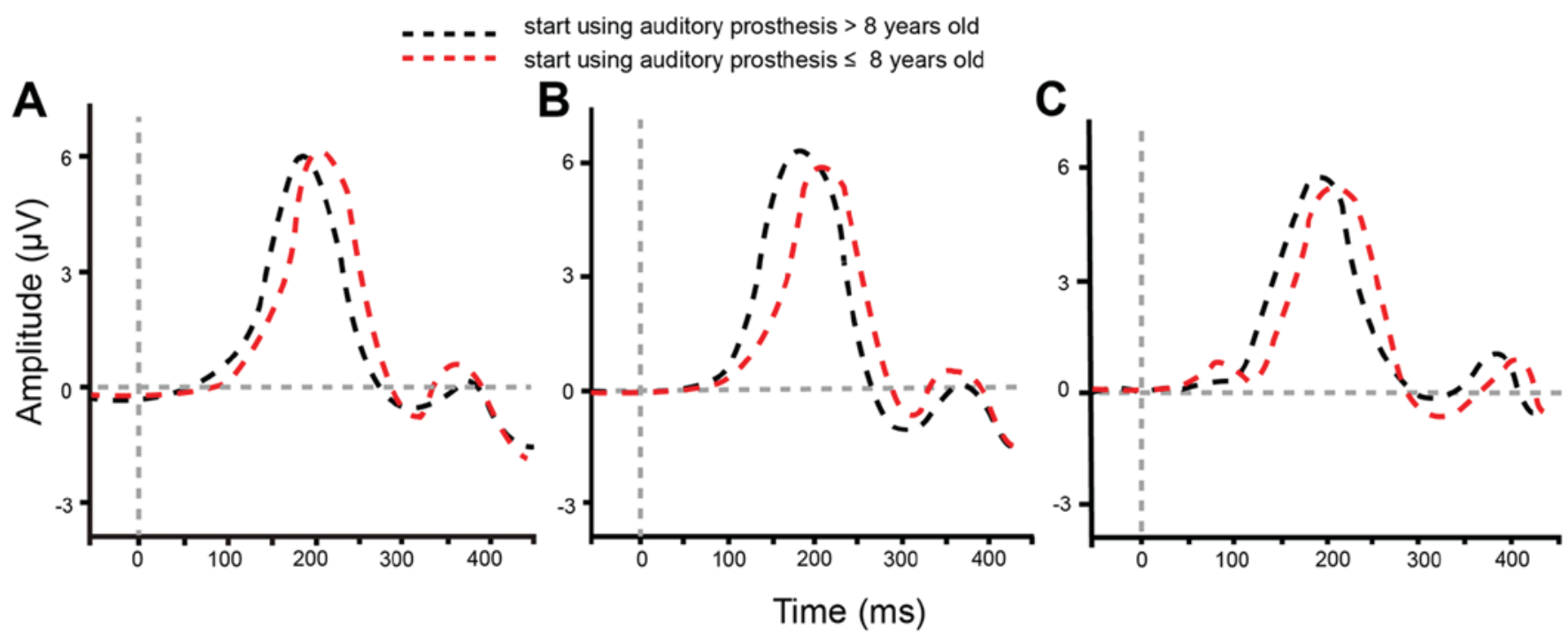

Figure 2. Waveforms of P1, N1 and P2 of auditory prosthesis users with initial age of use $\leq 8$ and $>8$ years. (A) $/ \mathrm{m} /,(\mathrm{B}) / \mathrm{g} /$ and $(\mathrm{C}) / \mathrm{t} /$ acoustic stimulations were used.

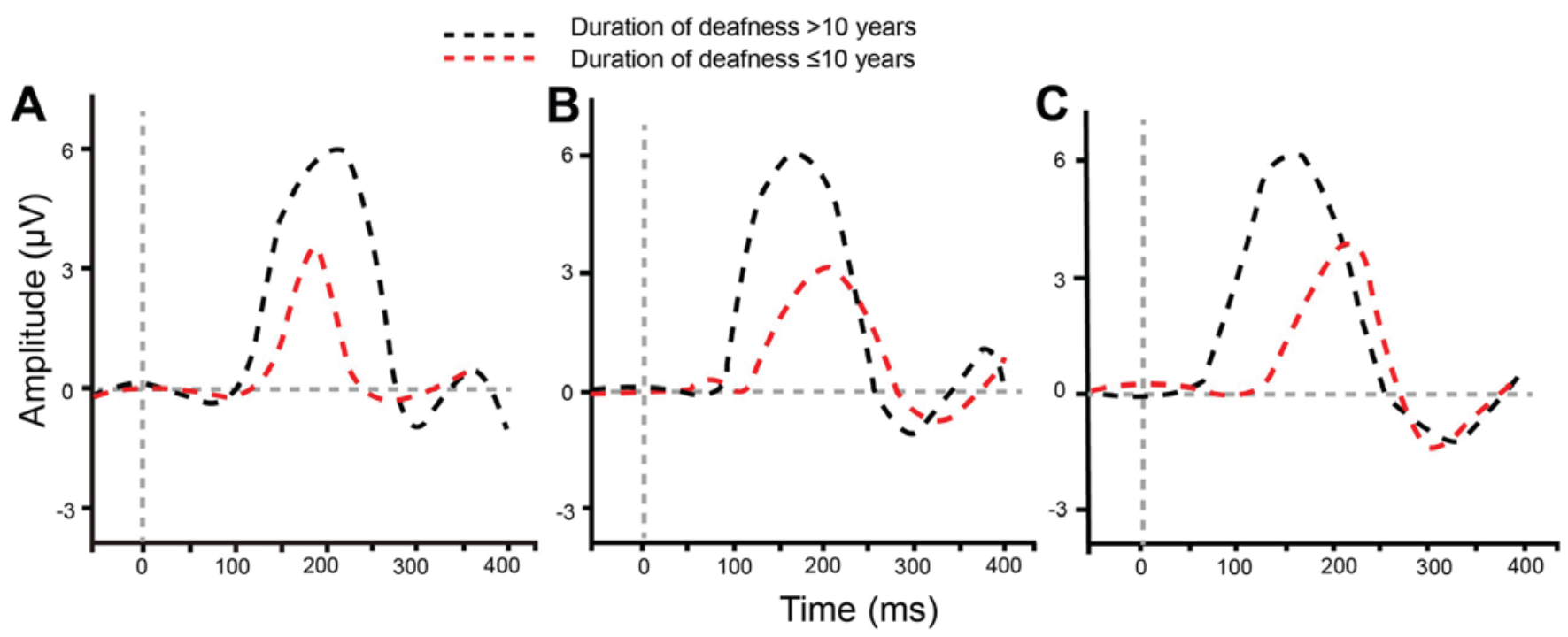

Figure 3. Waveforms of P1, N1 and P2 of auditory prosthesis users with different deafness durations. (A) /m/, (B)/g/ and (C)/t/ acoustic stimulations were used.

between latency and amplitude of P1 wave and time of using hearing aids under different stimuli was analyzed. Under the acoustic stimulations of $/ \mathrm{m} /, \mathrm{g} /$ and $/ \mathrm{t} /$, the P1 latency and amplitude of patients are presented in Table VII. According to the Pearson correlation analysis concerning latency and amplitude of P1 wave and usage time of auditory prosthesis, under the acoustic stimulation of $/ \mathrm{m} /$, latency and amplitude of P1 wave were both negatively associated with the usage time 
Table V. P1 latency of auditory prosthesis users who initially used the device at $\leq 8$ and $>8$ years of age.

\begin{tabular}{llcr}
\hline & \multicolumn{2}{c}{ P1 latency $(\mathrm{msec})$} & \\
\cline { 2 - 3 } $\begin{array}{l}\text { Acoustic } \\
\text { stimulation }\end{array}$ & $>8$ & $\leq 8$ & P-value \\
\hline$/ \mathrm{m} /$ & $129.42 \pm 8.09$ & $135.97 \pm 18.26$ & 0.015 \\
$\mathrm{lg} /$ & $124.59 \pm 15.50$ & $133.07 \pm 13.90$ & 0.002 \\
$\mathrm{t} / \mathrm{1}$ & $122.64 \pm 10.89$ & $134.19 \pm 12.87$ & $<0.001$ \\
\hline
\end{tabular}

Data are presented as the mean \pm standard deviation. Data were analyzed using one-way analysis of variance followed by a Bonferroni post hoc test (Calibration inspection level $\alpha=0.05 / 3=0.0167$ ).

Table VI. P1 latency of auditory prosthesis users who had $\leq 10$-year and >10-year deafness duration prior to using auditory prosthesis.

\begin{tabular}{lccr}
\hline & \multicolumn{2}{c}{ P1 latency $(\mathrm{msec})$} & \\
\cline { 2 - 3 } & $\begin{array}{l}>10 \text {-year } \\
\text { deafness } \\
\text { duration }\end{array}$ & $\begin{array}{c}\text { s10-year } \\
\text { deafness } \\
\text { duration }\end{array}$ & \\
stimulation & $128.68 \pm 9.27$ & $135.25 \pm 16.76$ & 0.021 \\
\hline$/ \mathrm{m} /$ & $125.24 \pm 14.56$ & $131.36 \pm 15.12$ & 0.033 \\
$\mathrm{lg} /$ & $123.23 \pm 11.02$ & $132.00 \pm 13.42$ & $<0.001$ \\
\hline $\mathrm{t} /$ & & & \\
\hline
\end{tabular}

Data are presented as the mean \pm standard deviation. Data were analyzed using one-way analysis of variance followed by a Bonferroni post hoc test (Calibration inspection level $\alpha=0.05 / 3=0.0167$ ).

Table VII. PI latency and amplitude under different acoustic stimulations.

\begin{tabular}{lcc}
\hline Acoustic stimulation & Latency $(\mathrm{msec})$ & Amplitude $(\mu \mathrm{V})$ \\
\hline$/ \mathrm{m} /$ & $133.11 \pm 15.02$ & $6.52 \pm 1.51$ \\
$\mathrm{~g} /$ & $129.37 \pm 15.16$ & $6.46 \pm 1.86$ \\
$\mathrm{lt} /$ & $129.15 \pm 13.30$ & $5.54 \pm 1.46$ \\
\hline
\end{tabular}

Data are presented as the mean \pm standard deviation.

of auditory prosthesis $(\mathrm{P}<0.05)$, with respective correlation coefficients of -0.222 and -0.774 ; provided acoustic stimulations were $/ \mathrm{g} /$ and $/ \mathrm{t} /$, no significant correlation existed between latency and amplitude of the P1 wave and usage time of auditory prosthesis (all $\mathrm{P}>0.05$; Table VIII).

SIR and CAP are associated with initial age of using auditory prosthesis and deafness duration. In terms of the initial age of use of auditory prosthesis, deafness duration and usage time of auditory prosthesis, 126 patients were divided into two groups. The rank-sum test was used to statistically analyze SIR and
CAP of the two groups under the same influencing factors (Table IX). The results demonstrated that SIR and CAP were significantly associated with the initial age of use of auditory prosthesis and deafness duration (both $\mathrm{P}<0.05$ ) but not with the usage time of auditory prosthesis $(\mathrm{P}>0.05)$.

\section{Discussion}

ACEPs are an emerging hearing aid evaluation tool for young children who fail to provide reliable behavioral feedback. It is effective in determining the association between the sensitivity of ACEPs and the sensation level of speech sounds, which is the ratio between the sum of detections and non-detections and the number of detections (11). P1, N1, and P2 are obligatory ACEP components, which are generated with input from the primary auditory cortex, auditory thalamocortical, cortico-cortical pathways and various association cortices (19). In the present study, via analysis of the P1-N1-P2 waves of the ACEP, the changes of the $\mathrm{P} 1$ wave were evaluated for auditory prosthesis users in order to investigate the feasibility of ACEP in clinical auditory effect assessment.

In the present study, under different acoustic stimulations, auditory prosthesis users had significantly higher extraction rates of the $\mathrm{P} 1$ wave than $\mathrm{N} 1$ and $\mathrm{P} 2$ waves; the auditory prosthesis users' shorter deafness duration prior to device usage and younger initial usage meant more marked P1-N1-P2 waveforms and longer P1 latency. A previous study noted that the P1 peak occurs at a latency of $\sim 300 \mathrm{msec}$ in infants with normal hearing; this latency decreases gradually until the end of the second decade of life, and at that time, P1 is observed at $\sim 60 \mathrm{msec}$ (13). The morphology and amplitude of the CAEP waveform are reported to vary with age, and the P1 of amplitude significantly decreases by adolescence (20). Additionally, in the present study, the amplification and latency of the P1 wave were both negatively associated with the usage time of auditory prosthesis under the acoustic stimulation of $/ \mathrm{m} /$. According to Alcántara et al, adults with severe deafness usually suffer hearing loss at high frequencies, leading to reduced audibility of speech signals of high frequency; therefore, once an auditory prosthesis is worn, the high-frequency acoustic stimulation cannot be recorded in auditory cortices with extended low-frequency response due to long-term stimulation by background noise (21).

In addition, SIR and CAP are associated with the initial age of use of auditory prosthesis and deafness duration. The SIR was used to provide a general outcome to measure speech production in various communicative contexts of real-life situations (22). CAP is designed to approximately describe how a child responds to sound from the cochlear implant; the lowest category represents no awareness of environmental sounds, whereas the highest category describes the ability to talk with a known speaker on a telephone in a nonlinear hierarchical scale (23). Long latency auditory evoked potentials (P1, N1, and P2) of exogenous cortical responses generated from primary or secondary auditory cortices (24). It has been verified that P1 latency changes with age and that P1 latency can be used as a biomarker for maturation of central auditory development in children (25). ACEP can reflect the neural detection of acoustic cues that are essential for speech perception (26). Additionally, as the P1 latency varies with different frequency 
Table VIII. Correlation of latency and amplitude of P1 wave and usage time of auditory prosthesis under different acoustic stimulations.

\begin{tabular}{|c|c|c|c|c|}
\hline \multirow[b]{2}{*}{ Acoustic stimulation } & \multicolumn{2}{|c|}{$\begin{array}{l}\text { P1 latency and usage } \\
\text { time of auditory prosthesis }\end{array}$} & \multicolumn{2}{|c|}{$\begin{array}{l}\text { P1 amplitude and usage } \\
\text { time of auditory prosthesis }\end{array}$} \\
\hline & $\mathrm{r}$ & P-value & $\mathrm{r}$ & P-value \\
\hline$/ \mathrm{m} /$ & -0.222 & 0.013 & -0.774 & $<0.001$ \\
\hline /g/ & 0.153 & 0.088 & -0.058 & 0.522 \\
\hline$/ \mathrm{t} /$ & -0.030 & 0.741 & -0.037 & 0.679 \\
\hline
\end{tabular}

Data are presented as the mean \pm standard deviation. Correlation analysis was conducted by Pearson correlation analysis. $r$, correlation coefficient; $r>0$, positively associated; $r<0$, negatively associated.

Table IX. Influence of different parameters on SIR and CAP.

\begin{tabular}{|c|c|c|c|c|c|}
\hline Parameter & Cases (n) & SIR & P-value & CAP & P-value \\
\hline Initial age of using auditory prosthesis (years) & & & 0.024 & & $<0.001$ \\
\hline$\leq 8$ & 71 & $3.23 \pm 1.01$ & & $6.76 \pm 1.52$ & \\
\hline$>8$ & 55 & $2.43 \pm 0.75$ & & $5.67 \pm 1.72$ & \\
\hline Deafness duration (years) & & & $<0.001$ & & 0.011 \\
\hline$\leq 10$ & 85 & $3.08 \pm 1.05$ & & $6.55 \pm 1.70$ & \\
\hline$>10$ & 41 & $2.46 \pm 0.68$ & & $5.74 \pm 1.56$ & \\
\hline Using time of auditory prosthesis (years) & & & 0.190 & & 0.153 \\
\hline$\leq 8$ & 113 & $2.84 \pm 0.98$ & & $6.23 \pm 1.71$ & \\
\hline$>8$ & 13 & $3.22 \pm 1.02$ & & $6.74 \pm 1.53$ & \\
\hline
\end{tabular}

Data are presented as the mean \pm standard deviation. Analysis was performed with an independent sample t-test. SIR, speech intelligibility rating; CAP, categories of auditory performance.

stimulations, it could effectively reflect a range of acoustic frequencies, making it necessary for speech recognition (25). A previous study further confirmed the result that children who have normal P1 latencies (normal-hearing or age-matched children) exhibit better speech perception in the multi-syllabic lexical neighborhood test than those with abnormal P1 latencies (27). Therefore, P1 latency may be used as a biomarker for central auditory development in hearing-impaired children, determining the effectiveness of intervention strategies for hearing-impaired children, as speech production and auditory perception are associated with the initial age of auditory prosthesis and deafness duration.

In conclusion, ACEP P1-N1-P2 waveforms and the development of the P1 wave were studied to evaluate their feasibility in assessing the effectiveness of an auditory prosthesis, which may be a theoretical foundation for clinical use. However, there were a limited number of samples, thus there was no completely representative result, and there was no separate discussion for patients who were wearing an auditory prosthesis and CI. For future studies, the authors will continue to collect cases and to study the application value of ACEP for hearing aids and CI children, which may provide more detailed references for the clinical application of ACEP and the evaluation of hearing recovery effects in clinically deaf children.

\section{Acknowledgements}

Not applicable.

\section{Funding}

Not applicable.

\section{Availability of data and materials}

The analyzed data sets generated during the present study are available from the corresponding author on reasonable request.

\section{Authors' contributions}

JDe, JDu and XM designed the present study. JDe and JDu performed the experiments. XM and PZ collected and analyzed the data, contributed to sample collection and provided intellectual input. JDe and JDu drafted and the manuscript. XM and PZ assisted with experimental design, interpreted the results and critically revised the manuscript. All authors read and approved the final version of the manuscript. 


\section{Ethics approval and consent to participate}

The present study was approved by the Ethics Committee of the First People's Hospital of Kunshan (Kunshan, China), and all patients provided written informed consent.

\section{Patient consent for publication}

All patients provided written informed consent.

\section{Competing interests}

The authors declare that they have no competing interests.

\section{References}

1. Richardson GP, de Monvel JB and Petit C: How the genetics of deafness illuminates auditory physiology. Annu Rev Physiol 73: 311-334, 2011.

2. Vivero RJ, Fan K, Angeli S, Balkany TJ and Liu XZ: Cochlear implantation in common forms of genetic deafness. Int J Pediatr Otorhinolaryngol 74: 1107-1112, 2010

3. Miao W, Li J, Tang M, Xian J, Li W, Liu Z, Liu S, Sabel BA, Wang $\mathrm{Z}$ and $\mathrm{He} \mathrm{H}$ : Altered white matter integrity in adolescents with prelingual deafness: A high-resolution tract-based spatial statistics imaging study. AJNR Am J Neuroradiol 34: 1264-1270, 2013.

4. Kaplan DM and Puterman M: Pediatric cochlear implants in prelingual deafness: Medium and long-term outcomes. Isr Med Assoc J 12: 107-109, 2010.

5. Kral A and O'Donoghue GM: Profound deafness in childhood. N Engl J Med 363: 1438-1450, 2010.

6. Fu S, Dong J, Wang C and Chen G: Parental attitudes toward genetic testing for prelingual deafness in China. Int J Pediatr Otorhinolaryngol 74: 1122-1125, 2010.

7. Vlastarakos PV, Proikas K, Papacharalampous G, Exadaktylou I, Mochloulis G and Nikolopoulos TP: Cochlear implantation under the first year of age-the outcomes. A critical systematic review and meta-analysis. Int J Pediatr Otorhinolaryngol 74 119-126, 2010.

8. Teoh SW, Pisoni DB and Miyamoto RT: Cochlear implantation in adults with prelingual deafness. Part II. Underlying constraints that affect audiological outcomes. Laryngoscope 114: 1714-1719, 2004.

9. Zheng Y, Soli SD, Wang K, Meng J, Meng Z, Xu K and Tao Y: A normative study of early prelingual auditory development. Audiol Neurootol 14: 214-222, 2009.

10. Jalilvand $H$, Pourbakht A and Jalaee $S$ : The relationship between hearing aid frequency response and acceptable noise level in patients with sensorineural hearing loss. Adv Biomed Res 4: 256, 2015.

11. Van Dun B, Carter L and Dillon H: Sensitivity of cortical auditory evoked potential detection for hearing-impaired infants in response to short speech sounds. Audiol Res 2: e13, 2012 .
12. Durante AS, Wieselberg MB, Carvalho S, Costa N, Pucci B, Gudayol N and Almeida KD: Cortical auditory evoked potential: Evaluation of speech detection in adult hearing aid users. Codas 26: 367-373, 2014 (In English, Portuguese).

13. Campbell JD, Cardon G and Sharma A: Clinical application of the P1 cortical auditory evoked potential biomarker in children with sensorineural hearing loss and auditory neuropathy spectrum disorder. Semin Hear 32: 147-155, 2011.

14. Thabet MT and Said NM: Cortical auditory evoked potential (P1): A potential objective indicator for auditory rehabilitation outcome. Int J Pediatr Otorhinolaryngol 76: 1712-1718, 2012.

15. Sharma A, Campbell J and Cardon G: Developmental and cross-modal plasticity in deafness: Evidence from the P1 and N1 event related potentials in cochlear implanted children. Int J Psychophysiol 95: 135-144, 2015.

16. Wagner M, Roychoudhury A, Campanelli L, Shafer VL, Martin B and Steinschneider M: Representation of spectro-temporal features of spoken words within the P1-N1-P2 and T-complex of the auditory evoked potentials (AEP). Neurosci Lett 614: 119-126, 2016.

17. Elangovan S and Stuart A: A cross-linguistic examination of cortical auditory evoked potentials for a categorical voicing contrast. Neurosci Lett 490: 140-144, 2011.

18. Lina-Granade G, Truy E, Porot M, Collet L and Disant F: Hearing impairment in children: Early diagnosis is essential. Arch Pediatr 7: 991-1000, 2000 (In French).

19. Guo S, Li H, Chen B and Dai C: Study of categories of auditory performance and speech intelligibility rating of post-lingual cochlear implantes. Lin Chung Er Bi Yan Hou Tou Jing Wai Ke Za Zhi 28: 955-957, 960, 2014 (In Chinese).

20. Gilley PM, Sharma A, Dorman M and Martin K: Developmental changes in refractoriness of the cortical auditory evoked potential. Clin Neurophysiol 116: 648-657, 2005.

21. Alcantara JL, Moore BC, Kühnel V and Launer S: Evaluation of the noise reduction system in a commercial digital hearing aid. Int J Audiol 42: 34-42, 2003.

22. Zhang VW, Ching TY, Van Buynder P, Hou S, Flynn C, Burns L, McGhie K and Wong AO: Aided cortical response, speech intelligibility, consonant perception and functional performance of young children using conventional amplification or nonlinear frequency compression. Int J Pediatr Otorhinolaryngol 78: 1692-1700, 2014

23. Lonka E, Hasan M and Komulainen E: Spoken language skills and educational placement in Finnish children with cochlear implants. Folia Phoniatr Logop 63: 296-304, 2011.

24. Russo N, Zecker S, Trommer B, Chen J and Kraus N: Effects of background noise on cortical encoding of speech in autism spectrum disorders. J Autism Dev Disord 39: 1185-1196, 2009.

25. Sharma A, Martin K, Roland P, Bauer P, Sweeney MH, Gilley P and Dorman M: P1 latency as a biomarker for central auditory development in children with hearing impairment. J Am Acad Audiol 16: 564-573, 2005.

26. Tremblay KL, Billings CJ, Friesen LM and Souza PE: Neural representation of amplified speech sounds. Ear Hear 27: 93-103, 2006.

27. Sharma A and Dorman MF: Central auditory development in children with cochlear implants: Clinical implications. Adv Otorhinolaryngol 64: 66-88, 2006.

28. Zhou H, Chen Z, Shi H, Wu Y and Yin S: Categories of auditory performance and speech intelligibility ratings of early-implanted children without speech training. PLoS One 8: e53852, 2013. 